nists. In: Miller RD (Ed.). Anesthesia, 3rd ed. New York: ChurchillLivingstone Inc, 1994: 430.

3 McCoy EP, Connolly F, Mirakhur RK, Loan PB, Paxton $L D$. Nondepolarizing neuromuscular blocking drugs and train-of-four fade. Can J Anaesth 1995; 42: 213-6.

4 Carrier J, Martin R, Pirlet M, Claprood $\Upsilon$, Tétrault JP. What is the best non-depolarizing relaxant to prevent succinylcholine fasciculations and myalgia! Can J Anaesth 1997; 44: A24.

\section{Density of cerebrospinal fluid and intrathecal spread}

To the Editor:

We read with interest the report by Lui et al. ${ }^{1}$ and would like to make a few comments. In spinal anaesthesia, regardless of the density/baricity of the drug solution, the volume of the solution is always the most immediate factor affecting the extent of spread due to simple "bulk replacement" or area contact, the greater the volume, the more extensive is the spread. In clinical doses, dilution into much larger volumes will not produce the lower levels of block that smaller volumes may. ${ }^{2,3}$ However, when a non-isobaric solution is used, the baricity/position interaction becomes the main determinant of the direction and speed of intrathecal spread. Since non-isobaric solutions in small volumes are commonly used, that may explain why volume of injectate is not a determinant of block height in most clinical settings. Density is the weight in grams of $1 \mathrm{~mL}$ of a solution at a specified temperature while baricity is the density of the solution relative to that of CSF. Thus, baricity, not the density, of the solution affects the spread. Since the density of CSF varies, the baricity of any given solution will vary. However, except for tetracaine, which is available in Iyophilised powder (niphanoid) form, spinal anaesthetics are aqueous solutions. They are generally formulated with sodium chloride to be isotonic and thus nearly isobaric. In practice, adding glucose produces hyperbaric solutions, diluting with water makes hypobaric solutions, and using only CSF to dissolve lyophilised tetracaine achieves the best possible isobaric solution.

Hwa-Kou King MD

LeMonte Wood MD

Department of Anesthesiology

King/Drew Medical Center

Charles R. Drew University of Medicine and Science Los Angeles, CA, USA

\section{REFERENCES}

1 Lui ACP, Polis TZ, Cicutti NJ. Densities of cerebrospinal fluid and spinal anaesthetic solutions in surgi- cal patients at body temperature. Can J Anaesth 1998; 45: 297-303

2 King H, Huntington C, Khan $A K$. Dose is the product of volume and concentration (Letter). Reg Anesth 1994; 19: 431-2.

3 King HK. Factors influencing subarachnoid block. Progress in Anesthesiology 1996; Vol X: 383-99.

\section{REPLY:}

Baricity is an important determinant of the distribution of spinal anaesthetic solutions as demonstrated in an in vitro study. ${ }^{l}$ Hence, knowledge of the densities of the local anaesthetic solutions relative to the densities of the cerebrospinal fluid (CSF) in the surgical population is a necessary first step. Although saline is isotonic, it is not isobaric, but is by definition, bypobaric. Likewise, tetracaine in saline solution is also bypobaric. ${ }^{2}$

Many other factors contribute to the final distribution which also depends on its dilution with CSF. Carpenter et al. ${ }^{4}$ demonstrated the correlation between lumbosacral CSF volume and sensory block height, concluding that the common diluent, namely CSF, is a major variable in determining local anaesthetic spread. In short, it is the dose of local anaesthetic, mixed with CSF (which bas high interindividual pariability in volume) that accounts for the variable block height observed in practice. There is little evidence to support volume of the solution as playing a major role in its distribution except for the situation where hypobaric solution is used to "float" the solution cephalad. In this instance, perhaps the phenomenon of "bulk replacement" that Drs. King and Wood alluded to might apply.

Anne C.P. Lui

Tomasz Z. Polis

Nicholas J. Cicutti

Department of Anaesthesia

Ottawa Hospital, Civic Site

Ottawa, Ontario

\section{REFERENCES}

1 Lui ACP, Munhall RJ, Winnie AP, Selander D. Baricity and the distribution of lidocaine in a spinal canal model. Can J Anaesth 1991; 38: 522-6.

2 Lui ACP, Polis TZ, Cicutti NJ. Densities of cerebrospinal fluid and spinal anaesthetic solutions in surgical patients at body temperature. Can J Anaesth 1998; 45: 297-303.

3 Stienstra R, Greene NM. Factors affecting the subarachnoid spread of local anesthetic solutions. Reg Anesth 1991; 16: 1-6. 